\title{
EFFECT OF STRUT THICKNESS ON ROOM AND HIGH TEMPERATURE COMPRESSIVE PROPERTIES OF BLOCK-TYPE Ni-Cr-Al POWDER POROUS METALS
}

\begin{abstract}
This study investigated the effect of strut thickness on the room and high temperature compressive properties of block-type $\mathrm{Ni}-\mathrm{Cr}-\mathrm{Al}$ powder porous metals with $\sim 3000 \mu \mathrm{m}$ pore size manufactured using a new powder process. Two block-type $\mathrm{Ni}-\mathrm{Cr}-\mathrm{Al}$ porous metals with different strut thicknesses were manufactured. The strut thicknesses of two block foams were $340 \mu \mathrm{m}$ (A) and $383 \mu \mathrm{m}$ (B), respectively. Room temperature, $500^{\circ} \mathrm{C}, 650^{\circ} \mathrm{C}$ and $800^{\circ} \mathrm{C}$ compressive tests were performed. The compressive results identified typical elastic, plateau and densification regions of foam material in all temperature conditions. Regardless of the strut thickness, compressive strength (maximum peak stress) decreased as deformation temperature increased. In all deformation temperature ranges, the compressive strength measured higher in the porous metal with greater strut thickness (B). The high temperature deformation behavior of powder porous metal was confirmed to be affected by the structural factor and microstructural factor of the porous metal. With the findings described above, this study also discussed the high temperature deformation mechanism of the $\mathrm{Ni}-\mathrm{Cr}-\mathrm{Al}$ metal foam based on fracture surfaces after the high temperature compressions.
\end{abstract}

Keywords: Ni-Cr-Al, Powder porous metal, Strut thickness, High temperature, Compressive behavior

\section{Introduction}

Porous material has an irregular or regular dispersion of pores composing $15-95 \%$ of the structure's volume. This material has the outstanding advantages of a greater specific surface area, ultra-light weight, high energy absorption and high liquid or air penetrability over other materials [1]. The porous materials that possess such properties are used in a broad range of industries such as post-processing of exhaust fumes, electrode body of fuel cell and heat exchanger industries.

Manufacturing processes of conventional porous metals include casting, foaming and reducing sintering [2-5]. However, conventional processes have difficulties in controlling pore size, even distribution and open type shape. The powder porous metals developed recently to overcome the limitations above. The process of new powder porous metals is reported to achieve such by spraying alloy powders on the surface of strut and sintering the preform [6]. It is easy to control the pore shape and alloy composition of powder porous metals, and the mechanical properties and high temperature properties of the porous metals can also be improved. Furthermore, the surface area increases due to the powders combined on the strut surface, and such can achieve greater catalyst properties compared to conventional porous metals [7]. Most powder porous metals are manufactured in the form of sheet, but with additional post processes, thick block-shaped porous metals can also be manufactured.
$\mathrm{Ni}-\mathrm{Cr}$-Al based alloys can generate a protective oxidation surface of $\mathrm{Al}_{2} \mathrm{O}_{3}$ and $\mathrm{Cr}_{2} \mathrm{O}_{3}$ due to the selective oxidation of $\mathrm{Al}$ and $\mathrm{Cr}$ in a high temperature oxidation atmosphere. The alloys can achieve outstanding high temperature mechanical properties in addition to excellent heat and oxidation resistances. Ni-Cr-Al based forms are expected to be used in various high temperature applications such as exhaust manifold of automobile, steam methane reforming (SMR), catalyst of filter and so on. There are nearly no studies reporting the manufacturing and properties of porous metal manufactured using $\mathrm{Ni}-\mathrm{Cr}-\mathrm{Al}$ based compositions.

Many studies have reported the manufacturing and mechanical properties of porous metal manufactured using conventional processes $[4,5]$. The authors of this study firstly reported the high temperature oxidation and mechanical properties of powder porous metal manufactured with $\mathrm{Fe}-\mathrm{Cr}-\mathrm{Al}$, Ni-Cr-Al and $\mathrm{Ni}-\mathrm{Fe}-\mathrm{Cr}-\mathrm{Al}$ compositions [6-8]. In general, porous metal's pore size and relative density are known to affect the mechanical properties of the material. However, no studies have reported the mechanical properties of porous metals with different strut thickness and similar pore size.

This study manufactured a bulk type Ni-Cr-Al based foam using a new manufacturing process of powder porous metal. The manufactured porous metal had different strut thicknesses and similar pore size. The room and high temperature compressive properties of these porous metals were evaluated, and also investigated the effect of strut thickness on mechanical properties.

\footnotetext{
* DONGYANG A.K KOREA CO., WONHAPGANG 1-GIL, SEJONG-SI, 30067, KOREA 


\section{Experimental}

To manufacture the powder porous metal used in this study, physical vapor deposition (PVD) and electroplating were applied to polyurethane (PU) foam to produce pure metal foam with identical pore size and shape. Then, Ni-Cr-Al powder and binder were additionally sprayed on the surface of pure metal foam, and a sheet-type powder porous metal was manufactured using sintering. The manufactured sheet-type porous metal was stacked in multiple layers to form a thick, bulk-type porous metal via an additional post-process. The pore size of the porous metals used in this study was approximately $3000 \mu \mathrm{m}$, but strut thickness was adjusted by varying electroplating time. From hereinafter, porous metal with thin strut is referred to as Foam A and metal with thick struts is referred to as Foam B.

X-ray fluorescence analysis (XRF; Rigaku, ZSX Primus II) was performed to identify the chemical compositions according to strut thickness, and the result is shown in Table 1. The analysis results found both Foam A and Foam B to have a similar composition of $\mathrm{Ni}-11 \% \mathrm{Cr}-4 \% \mathrm{Al}$ (wt.\%). Scanning electron microscope (SEM; Tescan, VEGA II LMU), energy dispersive spectroscopy (EDS) and micro-XRD (Rigaku, D/MAX RAPID-S) were used to observe the microstructure and to perform phase analysis.

TABLE 1

Chemical compositions of $\mathrm{Ni}-\mathrm{Cr}-\mathrm{Al}$ powder porous metals used in this study

\begin{tabular}{|c|c|c|c|c|c|}
\hline \hline Composition & Sample & Ni & Cr & Al & Si \\
\hline \multirow{2}{*}{ wt.\% } & Foam A & bal. & 11.45 & 4.56 & 0.41 \\
\cline { 2 - 6 } & Foam B & bal. & 11.16 & 4.28 & 0.04 \\
\hline
\end{tabular}

The Instron-8501 was used to evaluate the room temperature and high temperature compressive properties of the powder porous metal. As mentioned above, the powder porous metal used in this study was manufactured by stacking multiple sheets of powder porous metals in a thick block. As physical properties could vary according to the direction of stacking, compression tests were performed on two different samples - normal direction (ND) vertical to the sample and rolling direction (RD). In the case of ND direction, the tests were performed in $\mathrm{RT}, 500^{\circ} \mathrm{C}, 650^{\circ} \mathrm{C}$ and $800^{\circ} \mathrm{C}$ temperature conditions, and in the case of RD direction, RT and $800^{\circ} \mathrm{C}$ test conditions were used. The compression tests were performed in the condition of a $10^{-3} / \mathrm{sec}$ strain rate up to $60 \%$ compressive strain. Cylindrical samples were made along ND and RD directions that were $\phi 13 \mathrm{~mm}$ in diameter and $2.5 \mathrm{~mm}$ in height. After the compression tests, the samples underwent fracture surface analysis using SEM to identify the deformation mechanism of the porous metals.

\section{Results and discussion}

SEM results of the bulk-type powder porous metals are shown in Fig. 1 to observe the shape and structure of the materials. Both materials featured a three-dimensional net structure with an open cell type (all pores connected). Strut thicknesses measured $340 \mu \mathrm{m}$ and $383 \mu \mathrm{m}$ for Foam A and Foam B, respectively. The strut thickness of Foam B, which underwent a longer electroplating time, was confirmed to be greater. In general, pore structure, pore shape, relative density and intrinsic material's property are known to affect the physical properties of porous metals [1]. Therefore, a micro-CT scanner was used to measure relative density. The relative density of Foam A measured $7.97 \%$ and Foam B measured $10.23 \%$, which indicate that Foam B, with a greater strut thickness, had a greater relative density. The XRD analysis results of the powder porous metals are shown in Fig. 2. Regardless of strut thickness, both materials featured $\gamma$-Ni and $\gamma^{\prime}-\mathrm{Ni}_{3} \mathrm{Al}$ phases, and no other additional phases were found. It is generally known in the ternary $\mathrm{Ni}-\mathrm{Cr}-\mathrm{Al}$ system that a $\gamma^{\prime}-\mathrm{Ni}_{3} \mathrm{Al}$ precipitation strengthening phase having an L12 structure can be formed in a $\gamma$-Ni matrix [9]. Fig. 3 is high-magnification observa-
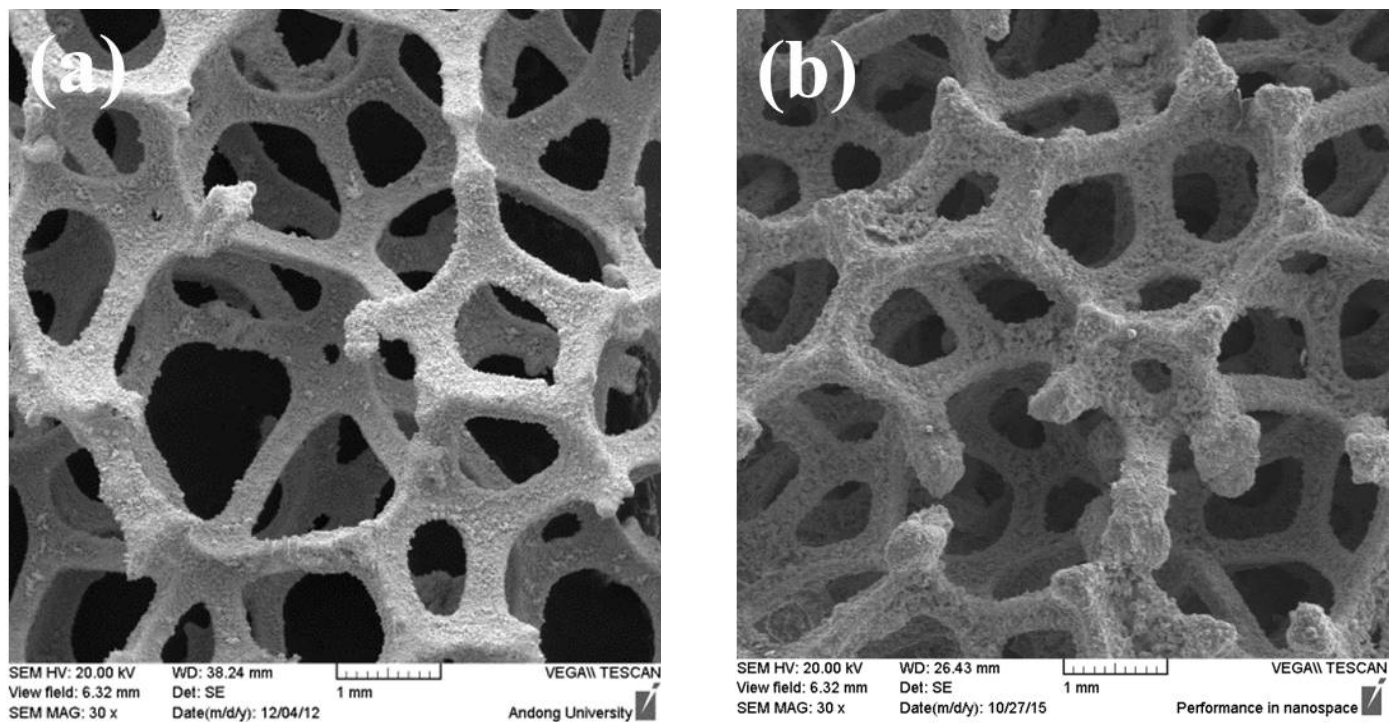

Fig. 1. Morphologies of Ni-Cr-Al powder porous metals; (a) Foam A and (b) Foam B 
tion results of the cross-sectional microstructure to identify the shape of the phases mentioned above. Both materials consisted of $\gamma$ and $\gamma^{\prime}$ phases. It was well corresponded to the results of XRD. However, the $\gamma^{\prime}$ phase size of Foam B, which has greater strut thickness, measured relatively smaller. This can be interpreted to have been caused by the different spraying characteristic of powders and the different effect of heat treatment according to strut thickness.

The room temperature compressive results of powder porous metal in ND and RD directions are shown in Fig. 4. In general, unlike general bulk materials, the compressive curves of porous metals (foams) are known to feature three unique areas (modes). These are a liner-elasticity area where stress increases as the strain increases, a plateau area where stress is maintained despite the increase in strain, and a densification area where stress increases dramatically after the breakage of struts by increasing strain [1]. In the case of ND direction, this

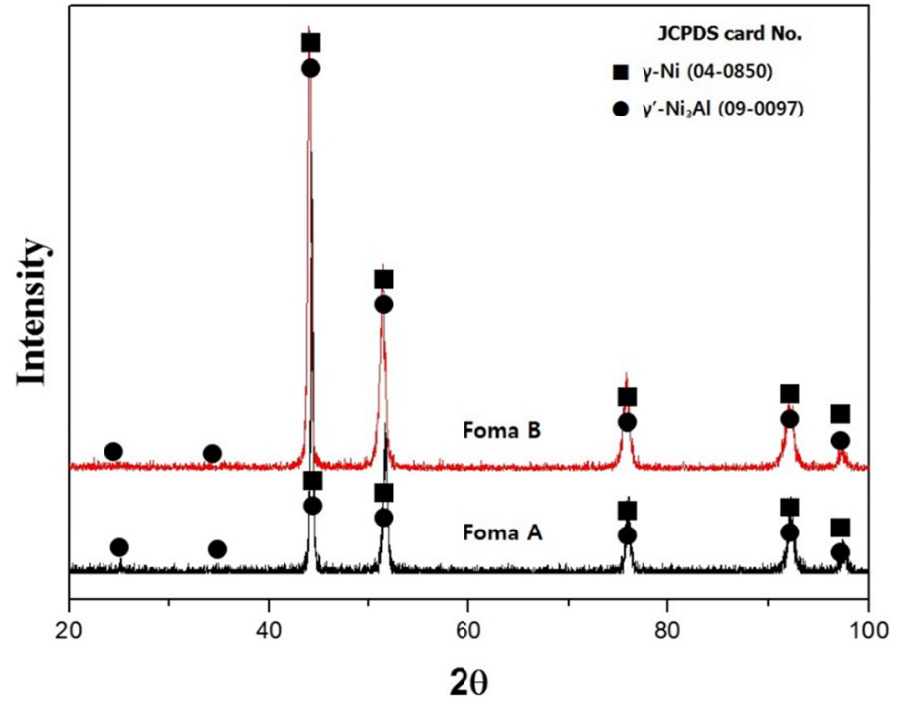

Fig. 2. XRD analysis results of Ni-Cr-Al powder porous metals
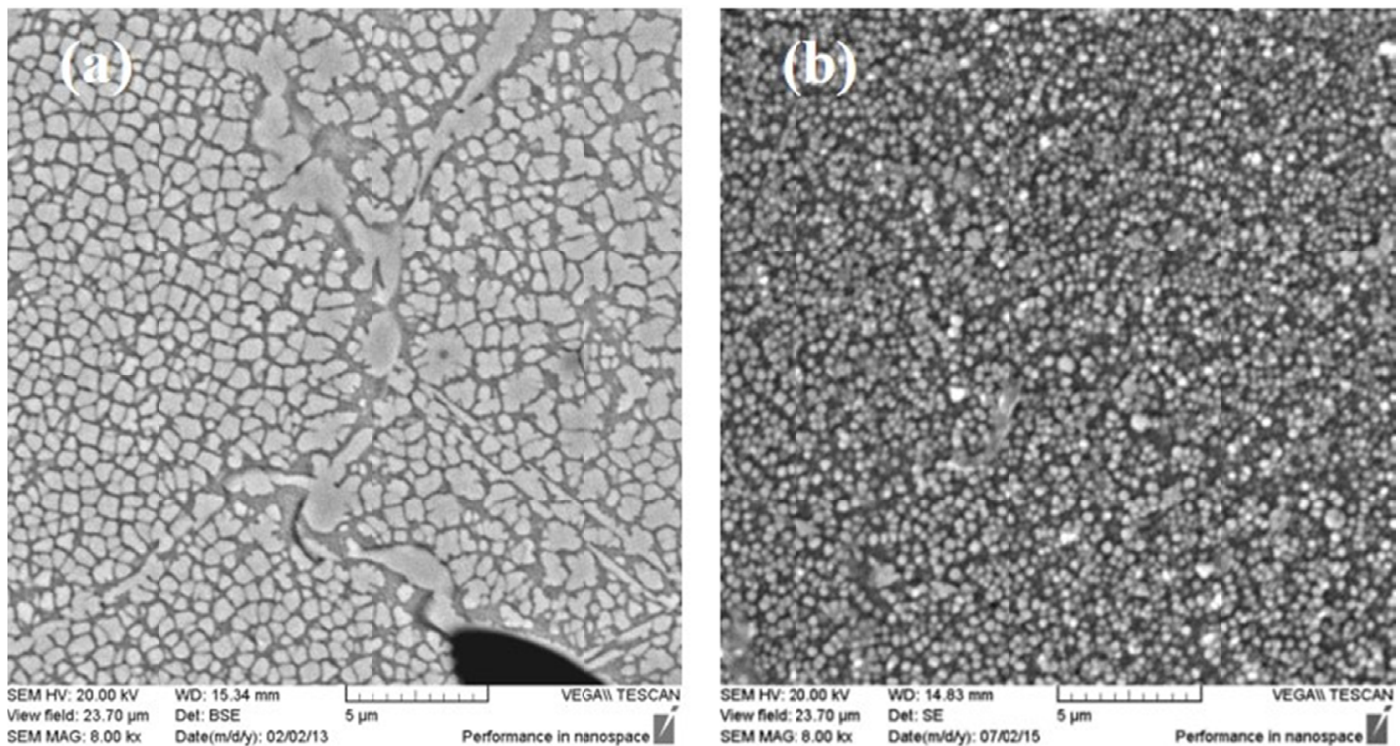

Fig. 3. Cross-sectional SEM observation results of Ni-Cr-Al powder porous metals (after etching; (a) Foam A and (b) Foam B

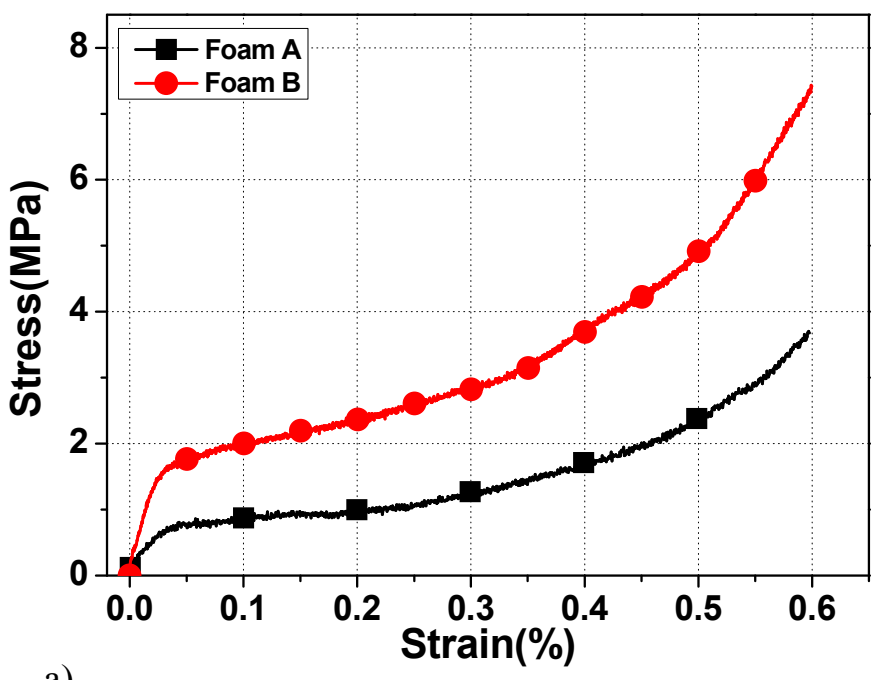

a)

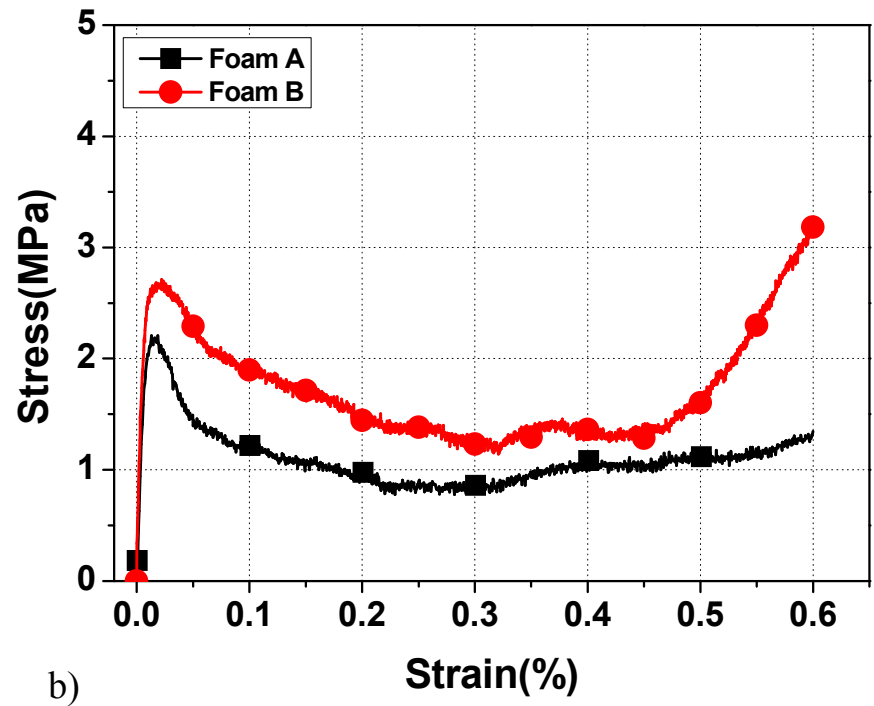

Fig. 4. Room temperature compressive results of Ni-Cr-Al powder porous metals in the (a) normal direction (ND) and (b) rolling direction (RD) 
study also found typical three modes shown in the normal porous metals: liner-elasticity, plateau and densification. However, RD direction showed a different compressive behavior compared to that of ND. There was a unique area where stress decreased as the strain increased (different from the plateau area where stress was maintained in ND direction) after the linear-elasticity area and maximum peak stress $\left(\sigma^{*}\right.$ peak $)$. As mentioned above, the block-type powder porous metal is manufactured by stacking multiple porous sheets. In the case of the RD, the joint areas in the interface between sheets were disconnected before inducing pore densification, and it was confirmed that stress decreased after the linear-elasticity area. A room temperature compressive strengths (maximum peak stresses, $\sigma_{\text {peak }}^{*}$ ) measured $0.75 \mathrm{MPa}$ in Foam $\mathrm{A}$ and $1.72 \mathrm{MPa}$ in Foam $\mathrm{B}$ in $\mathrm{ND}$, and $2.18 \mathrm{MPa}$ in Foam A and 2.69 MPa in Foam B in RD. In both ND and RD, Foam $\mathrm{B}$, with greater strut thickness, had higher room temperature compressive strengths (maximum peak stresses).

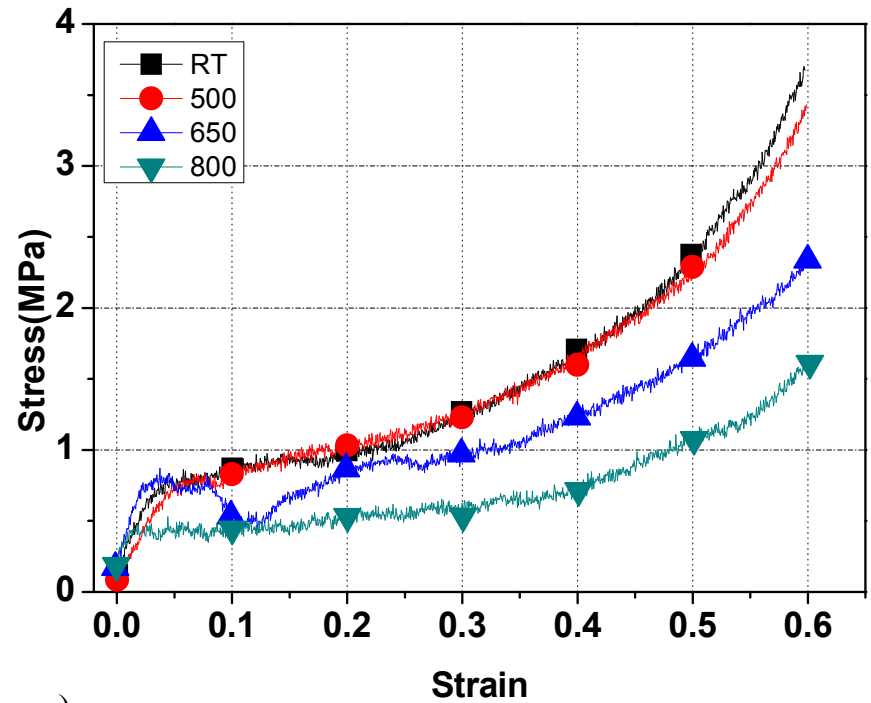

Fig. 5 shows the high temperature compressive results of powder porous metals in the ND direction. The liner-elasticity, plateau and densification areas mentioned above were also present in both Foam A and Foam B. Foam B, with greater strut thickness, showed higher compressive strength (maximum peak stress) compared to Foam A regardless of deformation temperature conditions. Fig. 6 shows the results of the room and $800^{\circ} \mathrm{C}$ temperatures compression tests in the $\mathrm{RD}$ direction for the two powder porous metals. When the room temperature and high temperature compressive curves were compared to each other, the $800^{\circ} \mathrm{C}$ high temperature condition identified the drastic strength (maximum peak stress) decrease. This is the proof that the bonding force between sheets becomes smaller at high temperature. In $\mathrm{RD}$ direction, Foam $\mathrm{B}$ with greater strut thickness had slightly higher maximum peak stress at $800^{\circ} \mathrm{C}$ than that of Foam $\mathrm{A}$.

Fig. 7 is the observation results of the fracture surface according to deformation temperature after the compression tests.

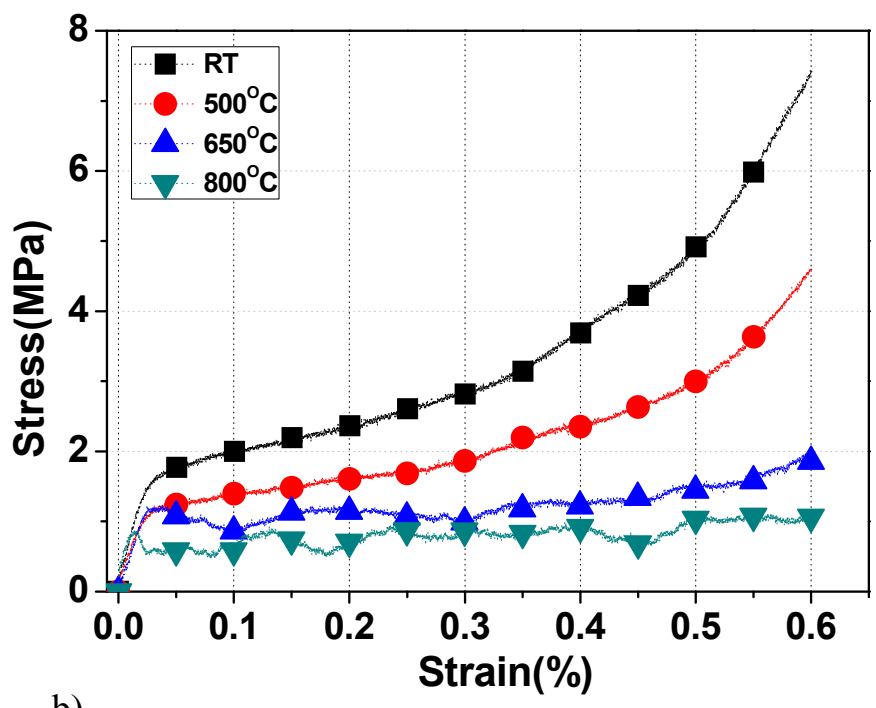

b)

Fig. 5. Room and high temperature compressive results of Ni-Cr-Al powder porous metals (ND direction); (a) Foam A and (b) Foam B
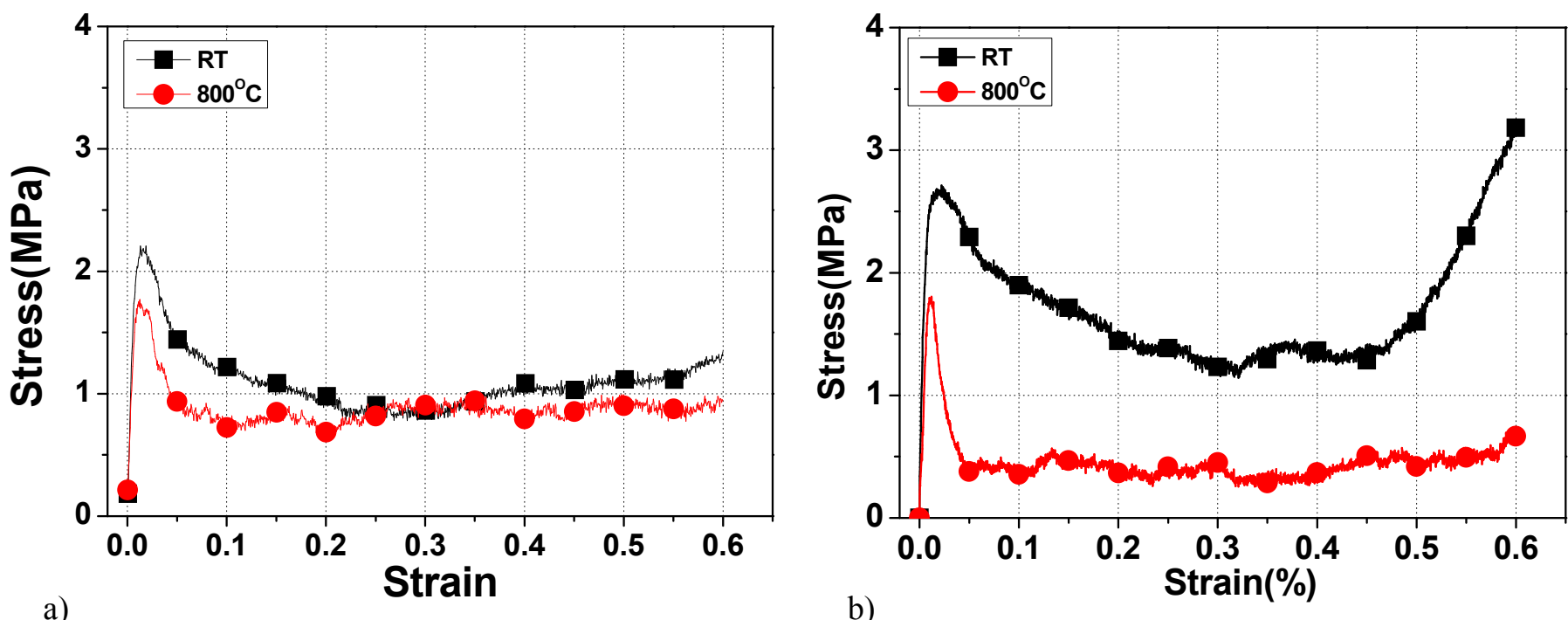

Fig. 6. Room and $800^{\circ} \mathrm{C}$ temperature compressive results of Ni-Cr-Al powder porous metals (RD direction); (a) Foam A and (b) Foam B 
Both Foam A and Foam B, after undergoing compression tests at room temperature, showed intergranular ductile fractures regardless of direction. Also, slip bands were observed within grains. The $500^{\circ} \mathrm{C}$ and $650^{\circ} \mathrm{C}$ temperature conditions in ND direction also showed intergranular ductile fractures in both materials. However, at a temperature of $800^{\circ} \mathrm{C}$, both Foam $\mathrm{A}$ and Foam B showed intergranular brittle fractures in ND and $\mathrm{RD}$. In general, a ductile fracture mode is known to be prone to occur as deformation temperature increases. Therefore, the brittle fracture mode observed in the $800^{\circ} \mathrm{C}$ test condition is assumed to be caused by the grain boundary embrittlement due to impurities frequently found in the Ni based alloy. In both Foam A and Foam $\mathrm{B}$, which have different strut thicknesses, similar fracture modes were observed in both ND and RD. Therefore, the fact that Foam $\mathrm{B}$, with greater strut thickness, has higher strengths than Foam A in all temperature conditions is assumed to be caused by the relatively greater density (structural factor of porous material) of Foam B. A microstructural factor (size difference of $\gamma^{\prime}$ phase) may also have a partial influence on the mechanical properties of the powder porous metal, but its influence is assumed to be trivial compared to structural factors.

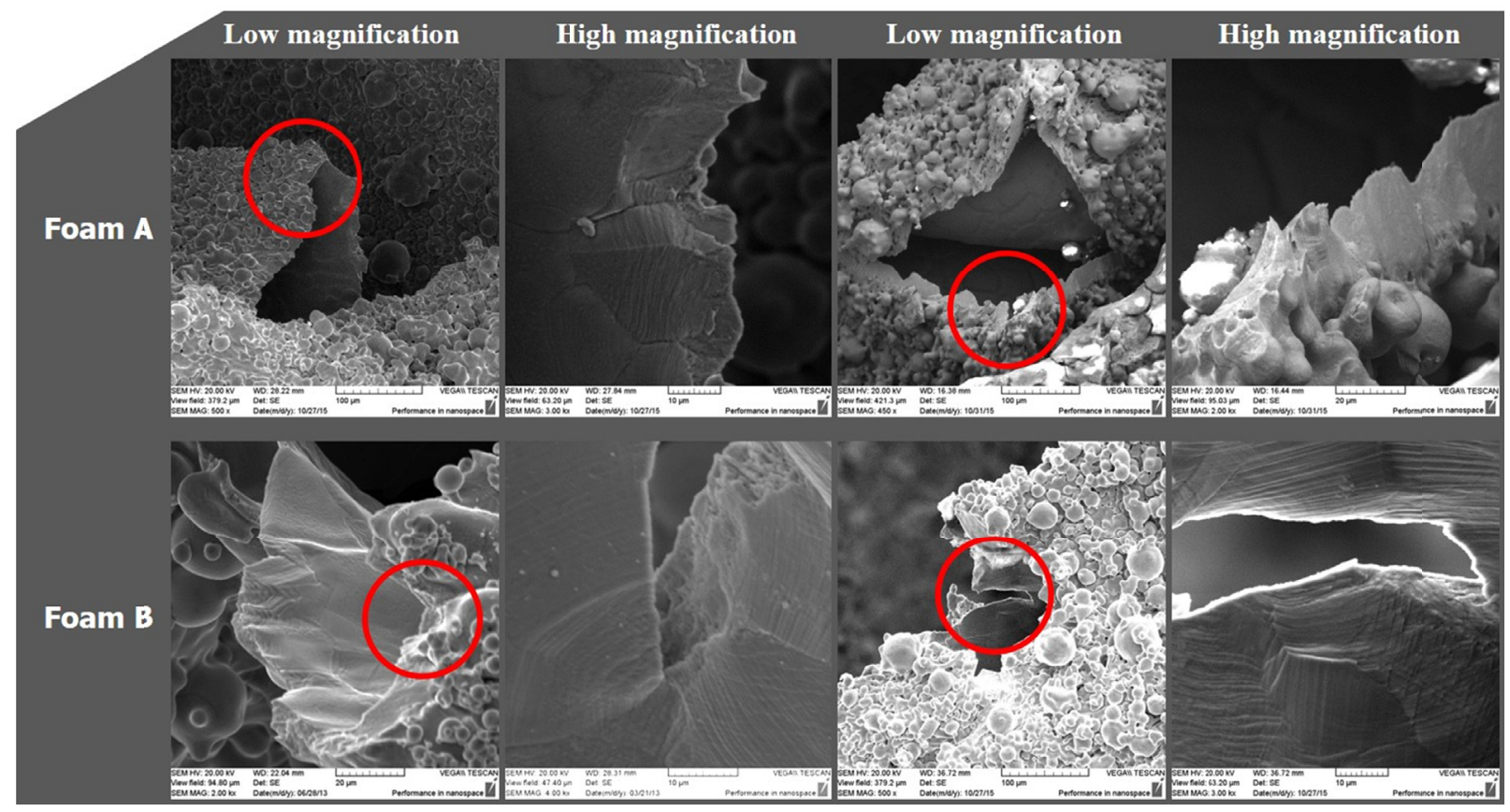

a)

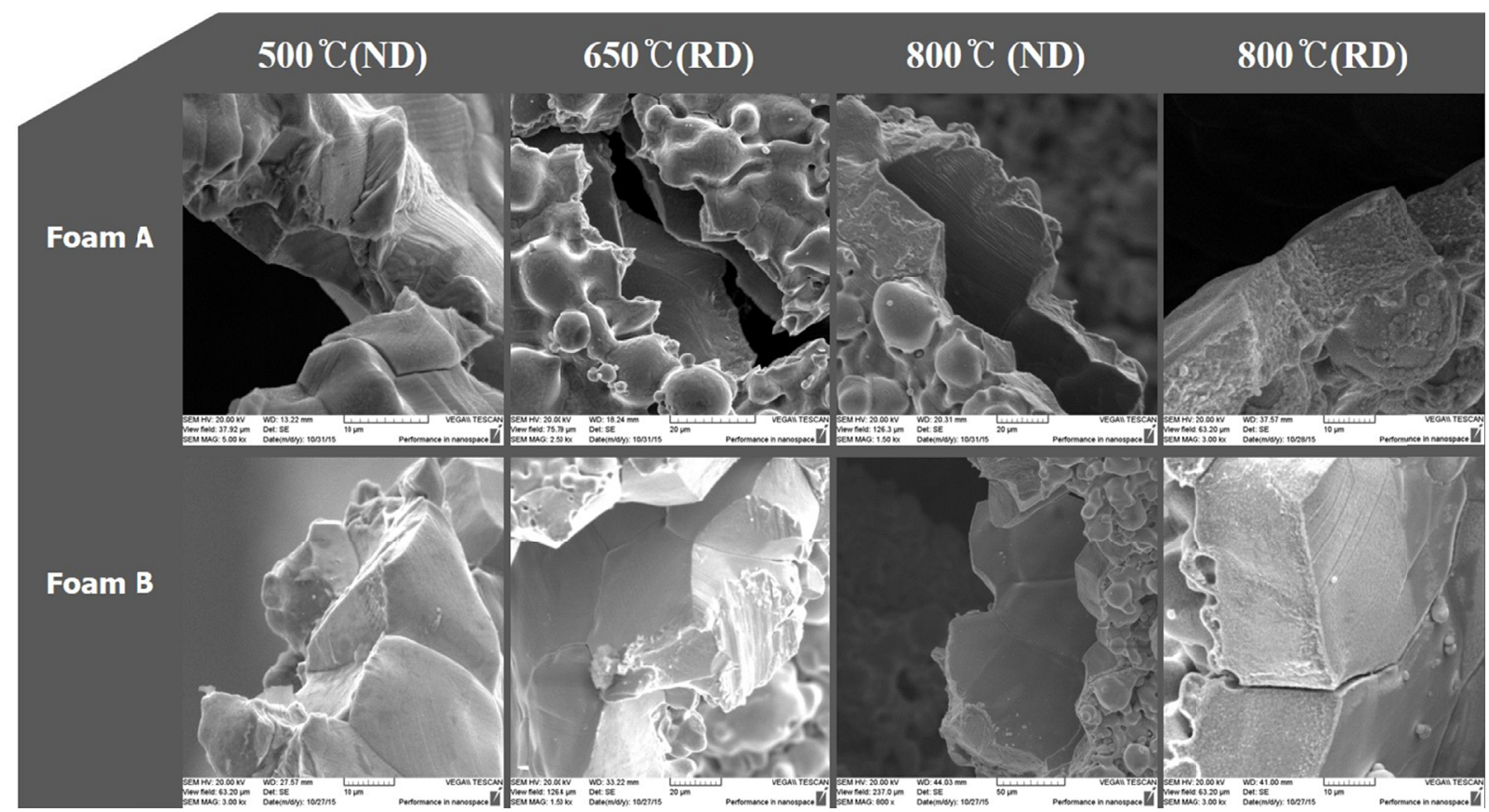

b)

Fig. 7. SEM fractography observation results of $\mathrm{Ni}-\mathrm{Cr}-\mathrm{Al}$ powder porous metals, compressed at (a) room temperature and (b) high temperatures 


\section{Conclusions}

This study manufactured powder porous metals with different strut thicknesses and similar pore size of $3000 \mu \mathrm{m}$ to identify the effect of strut thickness on compressive properties at room and high temperatures.

1. Foam A and Foam B, which have different strut thicknesses were manufactured by controlling the electroplating time of $\mathrm{Ni}-\mathrm{Cr}$-Al based porous metal. Foam B, which spent a longer time in electroplating, had greater strut thickness compared to Foam A, and its relative density was also greater. The phase analysis results confirmed that the two materials were composed of $\gamma$ and $\gamma^{\prime}$ phases regardless of strut thickness.

2. Room temperature and high temperature compressive results represented that Foam $B$ had higher strengths (maximum peak stresses) compared to Foam $\mathrm{A}$ in all temperature conditions and directions (ND, RD). It is commonly known that pore structure, pore shape, intrinsic material properties and relative density influence the mechanical properties of porous metals. In this study, Foam B, with a greater strut thickness, had greater relative density compared to Foam A, and the structural factor of the porous metal was confirmed to be the major cause of the change in strength properties.

3. Fracture surface observation confirmed intergranular ductile fractures in both Foam A and Foam B in room temperature, $500^{\circ} \mathrm{C}$ and $650^{\circ} \mathrm{C}$ conditions. However, at $800^{\circ} \mathrm{C}$, Foam $\mathrm{A}$ and Foam B both featured a intergranular brittle fracture mode. Even though the two materials had different strut thicknesses, they showed identical fracture modes in both normal and rolling directions in all temperature conditions. The brittle fracture mode found in the high temperature condition is assumed to have been caused by grain boundary embrittlement due to impurities in the Ni based alloy.

\section{Acknowledgments}

This research was supported by a grant from the Strategic Core Material Program funded by the Ministry of Trade, Industry and Energy, Republic of Korea.

\section{REFERENCES}

[1] L.J. Gibson, M.F. Ashby, Cellular solids: Structure and Properties, 2nd Ed. (Cambridge University Press, Cambridge, U.K., 1997).

[2] M.F. Ashby, A.G. Evans, N.A. Fleck, L.J. Gibson, J.W. Hutchinson, H.N.G. Wadley, Metal Foams: A design Guide (Butterworth Heinemann, Oxford, U.K., 2000).

[3] Wadley HNG, Cellular metals and metal foaming technology, (Verlag MIT, Germany, 2001).

[4] J. Bin, W. Zejun, Z. Naiqin, J. Scr. Mater. 56, 169 (2007).

[5] J. Zhou, P. Shrotriya, W.O. Soboyejo, J. Mech. Mater. 36, 781 (2004).

[6] S.H. Choi, J.Y. Yun, H.M. Lee, Y.M. Kong, B.K. Kim, K.A. Lee, J. Korean Powder Metall. Inst. 18, 122 (2011).

[7] J.S. Oh, M.C. Shim, M.H. Park, K.A. Lee, Met. Mater. Int. 20, 915 (2014).

[8] S.Y. Kim, S.H. Choi, J.Y. Yun, B.K. Kim, Y.M. Kong and K.A. Lee, Met. Mater. Int. 17, 983 (2011).

[9] C.O. Kim, J.S. Bae, K.A. Lee, J. Korean Powder Metall. Inst. 22, 93 (2015). 